\title{
Sobrevivência de espécies arbóreas plantadas em clareiras causadas pela colheita de madeira em uma floresta de terra firme no município de Paragominas na Amazônia brasileira
}

\author{
Jaqueline Macêdo GOMES ${ }^{1}$, João Olegário Pereira de CARVALHO², Marcela Gomes da SILVA³ , Deusa \\ Nara Viana NOBRE ${ }^{4}$, Marisol TAFFAREL 5 , Josué Evandro Ribeiro FERREIRA ${ }^{6}$, Raimundo Nonato Jesus \\ SANTOS $^{7}$
}

\begin{abstract}
RESUMO
Analisou-se a sobrevivência de mudas plantadas em 400 clareiras causadas por exploração florestal de impacto reduzido, em floresta de terra firme na Amazônia Oriental. Foram plantadas 3.818 mudas de 17 espécies, das quais apenas Schizolobium amazonicum não ocorre na área de estudo. A distância entre as mudas plantadas foi de aproximadamente $5 \mathrm{~m}$. As avaliaçóes ocorreram em 2005 e 2006. Com base na sobrevivência das mudas aos 11 meses após o plantio, as espécies indicadas para o enriquecimento de clareiras são: Schizolobium amazonicum, Cedrela odorata, Jacaranda copaia, Manilkara huberi, Astronium gracile, Pouteria bilocularis, Tabebuia impetiginosa, Pseudopiptadenia suaveolens, Cordia goeldiana, Parkia gigantocarpa, Simarouba amara, Sterculia pilosa, Laetia procera, Dinizia excelsa e Schefflera morototoni. Estudos sobre a taxa de crescimento, em períodos mais longos, são necessários para confirmar a utilização dessas espécies em plantios de enriquecimento de clareiras oriundas de exploração florestal, como alternativa para aumentar a produtividade e o valor econômico das florestas naturais manejadas na Amazônia brasileira.
\end{abstract}

PALAVRAS-CHAVE: Silvicultura pós-colheita, Tratamentos silviculturais, Enriquecimento em clareiras, Sobrevivência de espécies arbóreas, Floresta amazônica.

\section{Survival of seedlings planted in gaps after harvesting in a terra firme rain forest in Paragominas region in the Brazilian Amazonia}

\begin{abstract}
Survival of seedlings planted in 400 gaps created by reduced impact logging in a terra firme forest in the Eastern Amazonia was evaluated. 3,818 seedlings from 17 species occurring in the study area, except for Schizolobium amazonicum (paricá), which is rare in natural forests of Paragominas region, were planted in the gaps. Spacing of planted seedlings was $5 \mathrm{~m}$. According to survival of seedlings during 11 months after planting, the species Schizolobium amazonicum, Cedrela odorata, Jacaranda copaia, Manilkara huberi, Astronium gracile, Pouteria bilocularis, Tabebuia impetiginosa, Pseudopiptadenia suaveolens, Cordia goeldiana, Parkia gigantocarpa, Simarouba amara, Sterculia pilosa, Laetia procera, Dinizia excelsa and Schefflera morototoni can be suggested for enriching in gaps created by reduced impact logging. Complementary studies, mainly related to growth rates of seedlings, must be carried out and in a period longer than the present study to confirm the benefits of enrichment planting in gaps as an alternative to boost forest productivity and economic value of managed natural forest in the Brazilian Amazon.
\end{abstract}

KEYWORDS: Post-harvesting silviculture, Silvicultural treatments, Enrichment planting in gaps, Survival of tree species planted in gaps, Amazonian forest.

'Universidade Federal Rural da Amazônia. E-mail: jaquelinemacedogomes@hotmail.com

²Embrapa Amazônia Oriental / CNPq. E-mail: olegario.carvalho@gmail.com

3Universidade Federal Rural da Amazônia. E-mail: marcela.gsilva@gmail.com

${ }^{4}$ Universidade Federal Rural da Amazônia. E-mail: d_naraviana@yahoo.com.br

5Universidade Federal Rural da Amazônia. E-mail: sol_taffarel@yahoo.com.br

${ }^{6}$ Cikel Brasil Verde Madeiras Ltda. E-mail: evandro@cikel.com.br

${ }^{7}$ Cikel Brasil Verde Madeiras Ltda. E-mail: nonato@cikel.com.br 


\section{INTRODUÇÃO}

A floresta amazônica é detentora da maior biodiversidade do planeta, hoje ameaçada pela intensa e desordenada exploração de seus recursos, que coloca em risco de extinção tanto espécies vegetais quanto animais, até mesmo aquelas que ainda não foram descritas. Conciliar a conservação da biodiversidade com o desenvolvimento econômico é um dos grandes desafios que fomentam as pesquisas na área do desenvolvimento sustentável. Visando atingir esse desenvolvimento, algumas empresas madeireiras buscam técnicas de manejo adequadas a um melhor aproveitamento dos recursos da floresta e dentre essas técnicas estáo os tratamentos silviculturais.

A perturbação das áreas florestais causada pela colheita de madeira sem manejo adequado provoca danos e alteraçôes biofísicas e como resultado diminui o crescimento das árvores (Vidal et al., 2002). Em florestas exploradas é necessário praticar técnicas silviculturais para estimular a regeneração, o crescimento de mudas e árvores remanescentes que iráo compor as colheitas futuras.

Os tratamentos silviculturais aumentam o desenvolvimento de árvores em florestas tropicais. Pesquisas têm mostrado que o crescimento pode ser duplicado em relaçáo à floresta não tratada (Silva, 2001). Os principais tratamentos realizados em florestas tropicais são: corte de cipós, liberação de copas para maior captação de luz, condução da regeneração natural e o enriquecimento em clareiras.

Nas clareiras, a sucessão ecológica inicia com o aumento da radiação solar na floresta, provocando a germinação de sementes existentes no solo. A ausência da regeneração natural de espécies comerciais depois da colheita de madeira e a elevada competição dos indivíduos remanescentes com espécies sem valor de mercado são algumas das causas que póem em risco a sustentabilidade do manejo de florestas tropicais (Oliveira et al., 2006).

Enriquecer clareiras formadas após a exploração madeireira com espécies comerciais aumenta o valor econômico da floresta, a diversidade de espécies e ainda acelera o processo sucessional. Segundo Lamprecht (1990), o enriquecimento em florestas exploradas pode ser realizado no momento em que o número de indivíduos com valor econômico é insuficiente ou inexistente.

No planejamento dos tratamentos silviculturais, para que seja mantido o equilíbrio do ecossistema florestal, causando o mínimo de agressóes à comunidade tratada, alguns aspectos devem ser considerados como: composição florística, diversidade vegetal, padrão espacial das espécies, estrutura da floresta, crescimento dos indivíduos, recrutamento, mortalidade e todo o processo dinâmico de recuperação e reestruturação da floresta tratada (Carvalho, 2001).
Técnicas silviculturais são pouco utilizadas após a exploração madeireira, devido à inexistência de informaçóes suficientes sobre o assunto na Amazônia brasileira. Esse fato estimulou o desenvolvimento do Projeto "Silvicultura póscolheita na Amazônia brasileira" (Embrapa/UFRA/CNPq/ Cikel), no qual está contido o presente estudo, que tem por objetivo determinar a sobrevivência de mudas plantadas em clareiras formadas pela exploraçáo florestal.

\section{MATERIAIS E MÉTODOS}

\section{ÁREA DE ESTUDO}

O estudo de plantio em clareiras faz parte do Projeto "Silvicultura pós-colheita na Amazônia brasileira" que está sendo realizado em 700 ha de floresta na Fazenda Rio Capim, que pertence a Cikel Brasil Verde Madeiras Ltda. (Cikel), localizada no município de Paragominas - PA, distante cerca de $320 \mathrm{~km}$ de Belém. A área experimental sofreu exploração de impacto reduzido em 2004.

O clima da regiáo é do tipo "Aw", segundo a classificação de Köeppen, com precipitação pluviométrica média anual de $1766 \mathrm{~mm}$, temperatura média anual de $27,2^{\circ} \mathrm{C}$ e umidade relativa do ar de $81 \%$ (Watrin \& Rocha, 1992).

Segundo Sombroek (1986), a área onde se encontra o município de Paragominas apresenta uma topografia que vai de plana a suavemente ondulada. Os principais solos na regiấo de acordo com Rodrigues et al. (2003) são: Latossolos Amarelos; Argissolos Amarelos; Plintossolos; Gleissolos; e Neossolos. Os solos possuem baixa fertilidade, devido à baixa reserva de nutrientes como cálcio, magnésio, potássio, fósforo e nitrogênio, além de alta saturaçáo por alumínio (Rodrigues et al. 2003).

O município de Paragominas é drenado pelas bacias do rio Capim e do rio Gurupi, servindo este último de divisa com o Estado do Maranhão (Watrin\& Rocha, 1992). Outros rios de menor porte drenam a área, tais como Ananavira, Paraquequara, Candiru-Açu, Potiritá, Piriá, Uraim e Surubiju, entre outros (Leal, 2000). A tipologia da área onde foram instalados os tratamentos silviculturais é Floresta Ombrófila Densa, também chamada de Floresta Equatorial Úmida de Terra Firme (Veloso et al., 1991).

\section{AMOSTRAGEM}

O Projeto "Silvicultura pós-colheita na Amazônia brasileira" é constituído por sete tratamentos instalados em 700 ha na fazenda Rio Capim. Em dois desses tratamentos (T4 e T5) foi feito o plantio de mudas de espécies arbóreas em clareiras causadas pela exploração florestal.

Foram selecionadas 400 clareiras com áreas variando de $250 \mathrm{~m}^{2}$ a $600 \mathrm{~m}^{2}$. O critério para estabelecer o número de clareiras para o estudo foi de que a quantidade de clareiras 
enriquecidas (adensadas com plantio de mudas) seria no máximo 50\% do número de árvores colhidas por hectare. Portanto, considerando que foram derrubadas, em média, cinco árvores por hectare na área de estudo, foram selecionadas em média, duas clareiras por hectare. As clareiras selecionadas foram identificadas com piquetes na entrada de cada clareira, com as seguintes informaçôes: número do tratamento, número da repetição e número da clareira, por exemplo, a clareira de número 3 (C3) da repetição de número 2 (R2) do tratamento 4 (T4) foi identificada assim: T4R2C3.

\section{SELEÇÃO DE ESPÉCIES, PREPARO DE MUDAS E PLANTIO}

As espécies plantadas foram selecionadas de acordo com informações obtidas sobre o seu crescimento em altura e em diâmetro e com base na lista de espécies exploradas pela empresa Cikel. Foram plantadas 3.818 mudas de crescimento rápido (média de 9 a 10 plantas por clareira), ocorrentes na Fazenda Rio Capim, com exceçáo de Schizolobium amazonicum (Huber) Ducke (paricá), que raramente ocorre naquela regiáo. $\mathrm{O}$ número de mudas plantadas por espécie variou de acordo com a sua disponibilidade na ocasião da implantaçấo do experimento. As mudas foram plantadas aleatoriamente nas clareiras, obedecendo uma distância de aproximadamente $5 \mathrm{~m}$ entre elas.

As mudas utilizadas no plantio foram transplantadas de estradas secundárias e ramais de arraste, com exceção das mudas de Schizolobium amazonicum que foram produzidas no viveiro da Cikel. As mudas, tanto as produzidas em viveiro como as transplantadas, estavam com altura variando de 3 $\mathrm{cm}$ a $260 \mathrm{~cm}$ na ocasião do plantio. Na produção das mudas foi utilizada apenas terra preta como substrato. Em nenhum momento houve aplicação de adubo químico.

\section{MONITORAMENTO E ANÁLISE DOS DADOS}

Nos meses de março e abril de 2005 teve início o monitoramento com a primeira avaliaçáo dos tratamentos relacionados às clareiras. A segunda avaliação foi realizada em março de 2006, com uma média de 11 meses e 16 dias após o plantio.

Nas duas ocasiōes foram feitas limpezas nas clareiras para impedir o estabelecimento de espécies indesejáveis que poderiam prejudicar o crescimento das mudas plantadas.

\section{RESULTADOS E DISCUSSÃO}

As espécies utilizadas no plantio de enriquecimento das clareiras são apresentadas na Tabela 1 , com os respectivos números de mudas plantadas e a porcentagem de sobrevivência após 11 meses e 16 dias do plantio.

As espécies com maior número de mudas plantadas foram Schizolobium amazonicum (Huber) Ducke (paricá), Cedrela odorata L. (cedro-vermelho), Tabebuia impetiginosa (Mart. Ex DC.) Standl. (ipê-roxo), Manilkara huberi (Ducke) A. Chev. (maçaranduba), Parkia gigantocarpa Ducke (fava-atanã) e Simarouba amara Aubl. (marupá).

A maioria das espécies plantadas alcançou alta sobrevivência no período de estudo, principalmente por serem espécies consideradas intolerantes à sombra, portanto bem adaptadas às condiçôes ambientais proporcionadas pelas clareiras. Apenas as espécies Pouteria bilocularis, Manilkara huberi e Astronium gracile foram consideradas por Carvalho $(1992,2000)$ como

Tabela 1 - Número (N) de mudas plantadas em clareiras causadas pela exploração de impacto reduzido na Fazenda Rio Capim, em 2005, e sua percentagem de sobrevivência (S\%) aos 11 meses e 16 dias após o plantio.

\begin{tabular}{|c|c|c|c|}
\hline Nome científico & Nome comum & $\begin{array}{c}\mathrm{N} \\
(2005) \\
\end{array}$ & $\begin{array}{c}\mathrm{S} \\
(\%)\end{array}$ \\
\hline Astronium gracile Engl. & Muiracatiara & 31 & 90 \\
\hline Bagassa guianensis Aubl. & Tatajuba & 64 & 89 \\
\hline Caryocar villosum (Aubl.)Pers. & Piquiá & 19 & 47 \\
\hline Cedrela odorata L. & Cedro & 469 & 93 \\
\hline Cordia goeldiana Huber & Freijó-cinza & 64 & 89 \\
\hline Dinizia excelsa Ducke & Angelim-vermelho & 92 & 78 \\
\hline Jacaranda copaia (Aubl.) D. Don. & Parapará & 23 & 91 \\
\hline Laetia procera (Poepp) Eich. & Pau-jacaré & 19 & 84 \\
\hline Manilkara huberi (Ducke) A. Chev. & Maçaranduba & 156 & 87 \\
\hline Parkia gigantocarpa Ducke & Fava-atanã & 146 & 86 \\
\hline Pouteria bilocularis (H. Winkl.) Baehni & Goiabão & 22 & 82 \\
\hline Pseudopiptadenia suaveolens (Miq.) J.W.Grimes & Timborana & 12 & 100 \\
\hline Schefflera morototoni (Aubl.) Lecne Planch & Morototó & 60 & 75 \\
\hline Schizolobium amazonicum (Huber) Ducke & Paricá & 2240 & 92 \\
\hline Simarouba amara Aubl. & Marupá & 119 & 90 \\
\hline Sterculia pilosa Ducke & Envira-quiabo & 47 & 94 \\
\hline Tabebuia impetiginosa (Mart. Ex DC.) Standl. & Ipê-roxo & 235 & 93 \\
\hline
\end{tabular}


tolerantes à sombra, seguindo a classificação de Swaine \& Whitmore (1988).

Schizolobium amazonicum (Figura 1) é uma espécie que vem sendo utilizada há muito tempo na regiáo amazônica, tanto em plantios homogêneos ou mistos em pleno sol como em enriquecimento de capoeiras (Sabogal et al., 2006), pois se adapta em locais de alta luminosidade e tem rápido crescimento.

No presente estudo, sua sobrevivência foi de $92 \%$. Na mesma fazenda, cerca de $60 \mathrm{~km}$ da área deste estudo, porém em plantio puro e em plena luz, Gasparin et al. (2008) registraram $100 \%$ de sobrevivência da espécie, aos 19 meses após o plantio. Em projetos de reposição florestal avaliados por Galeão et al. (2006), foi observada uma taxa de sobrevivência de $98 \%$ para S. amazonicum em Portel, PA, com 2 anos de idade e em Dom Elizeu, PA, com 3 anos de idade. Nos projetos de Dom Elizeu, a sobrevivência diminuiu com a idade do plantio. Por exemplo, aos 5 anos de idade a sobrevivência foi de $95 \%$ e aos 6 anos foi de $93 \%$. Porém, nos projetos em São Miguel do Guamá, PA, aos 3 anos de idade, a sobrevivência foi de $84 \%$ e aos 5 anos foi de $50 \%$.

$\mathrm{Na}$ avaliação de experiências silviculturais nos estados do Amazonas, Mato Grosso, Pará e Rondônia, realizada por Sabogal et al. (2006), foi observada uma sobrevivência média de $66 \%$, para a espécie em plantios em floresta explorada, taxa considerada baixa pelos autores, pois nas áreas anteriormente usadas com pastagem ou agricultura ou mesmo capoeira a sobrevivência foi em torno de $94 \%$.

Em pesquisa realizada por Meneses-Filho et al. (1995), foi observada a taxa de sobrevivência de apenas $33 \%$ para a espécie aos sete anos após o plantio em linhas na capoeira do Parque Zoobotânico da Universidade Federal do Acre. Os autores comentam que a taxa de sobrevivência de $S$. amazonicum verificada no Parque Zoobotânico pode aumentar desde que a espécie seja manejada de forma correta.

De um modo geral, a sobrevivência da espécie, tanto nas pesquisas quanto nos projetos de reposição florestal, foi sempre maior nos plantios em plena luz, chegando até a 100\%. Portanto, embora a taxa observada nas clareiras na Fazenda Rio Capim (92\%) seja animadora, há necessidade de continuar o monitoramento por um período mais longo.

Há a necessidade também de um acompanhamento fitossanitário do S. amazonicum na Fazenda Rio Capim, pois segundo Sabogal et al. (2006), os plantadores da espécie no Pará estão enfrentando um grande problema com a praga conhecida como mosca-da-madeira (Rhaphiorhynchus pictus), que impossibilita o aproveitamento da madeira e está presente em $42 \%$ dos plantios, e em Rondônia plantios inteiros estão sendo dizimados pela praga.

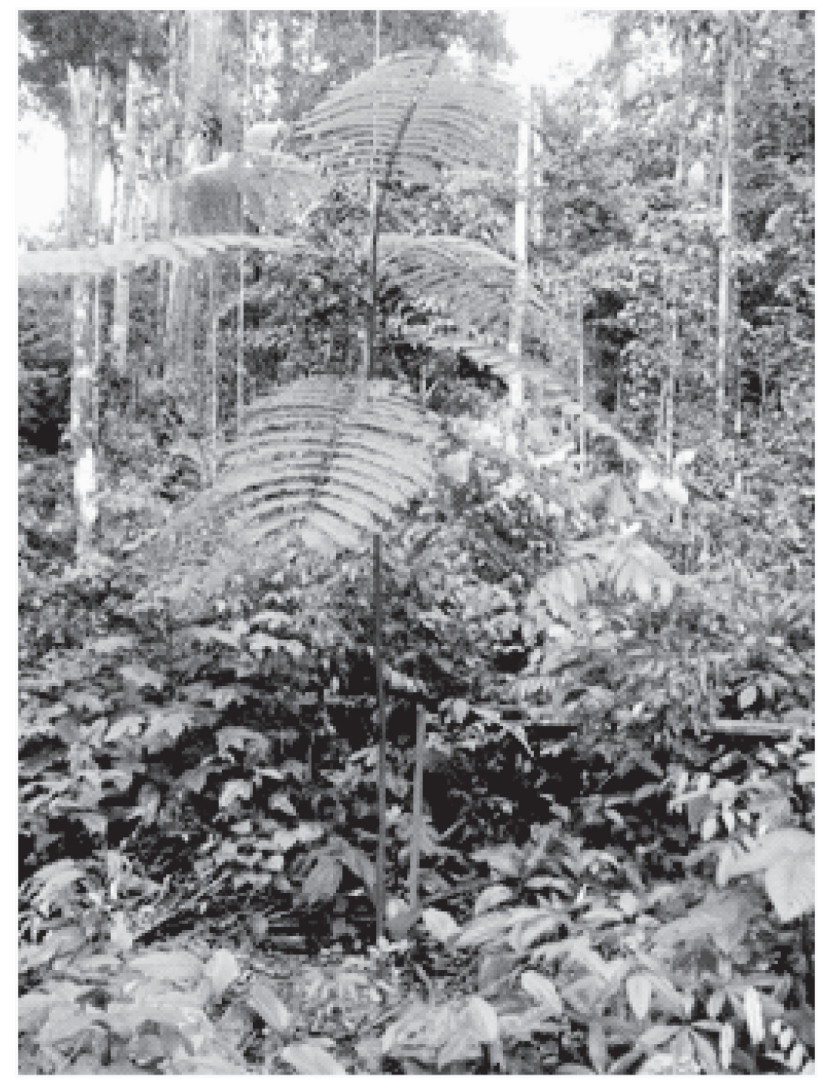

Figura1 - Schizolobium amazonicum (Huber) Ducke

A espécie com o segundo maior número de mudas plantadas foi Cedrela odorata (Figura 2), que obteve alta sobrevivência (93\%). Apesar de ser uma espécie muito suscetivel ao ataque da Hypsipyla grandella Zeller, na área de estudo não foram observados ataques que viessem a prejudicar o seu desenvolvimento, fato que incentiva o plantio da espécie em clareiras formadas pela exploração madeireira. Ohashi et al. (1993) recomendam o plantio de C. odorata em florestas exploradas, desde que seja realizada a manutenção do plantio com práticas que reduzam a competição com outras espécies. Tais práticas são: eliminação de cipós que estejam sufocando os indivíduos plantados; eliminaçáo de árvores com valor econômico e ecológico desconhecido que estejam prejudicando o desenvolvimento das mudas plantadas; e eliminação de bifurcaçôes dos indivíduos plantados para concentrar o crescimento em um só broto.

Jacaranda copaia alcançou sobrevivência de 91\%. Provavelmente, esse desempenho tenha sido devido à espécie pertencer ao grupo de intolerantes à sombra, conseqüentemente necessita de grande quantidade de radiação solar em sua fase inicial de desenvolvimento, portanto se beneficia da luz nas clareiras. Serrão et al. (2003) encontraram sobrevivência de $85 \%$ em mudas transplantadas de dentro da 


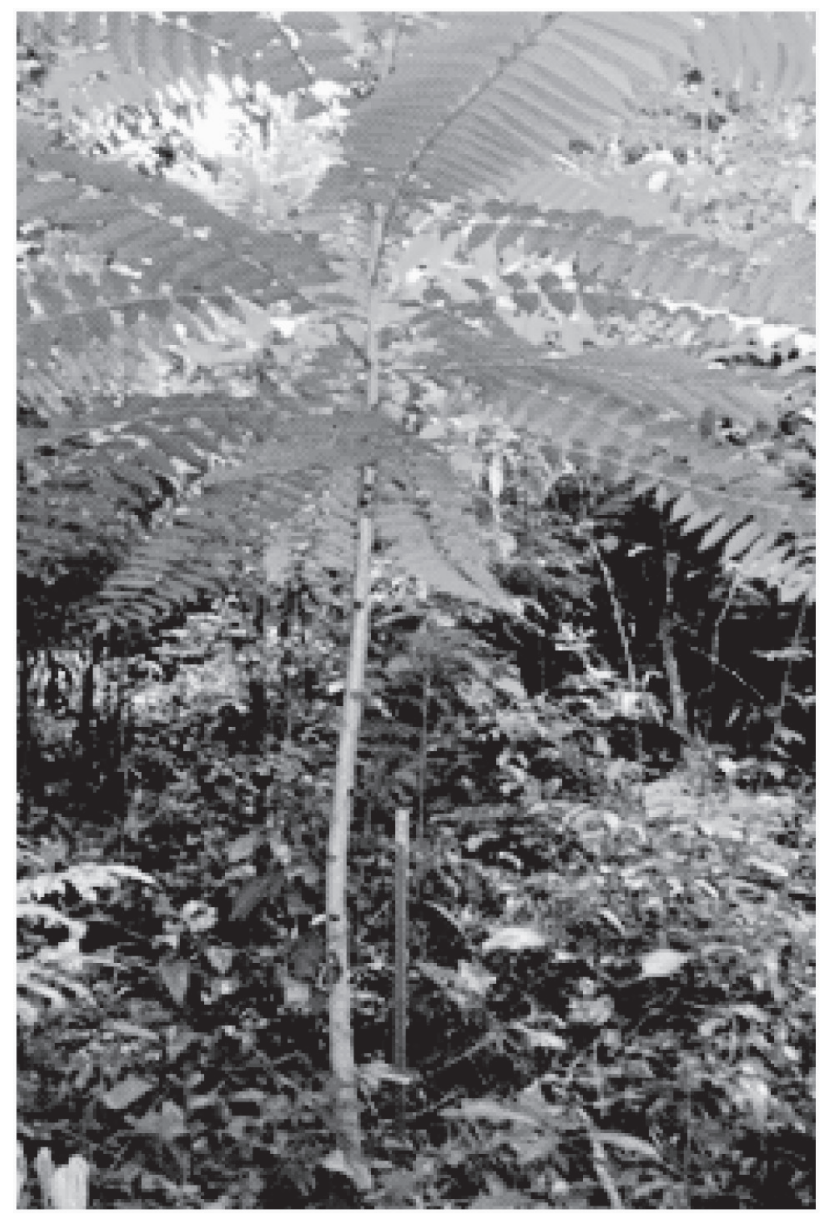

Figura 2: Cedrela odorata L.

mata densa para o centro de clareiras originárias de exploração seletiva, no município do Moju. Nessa mesma floresta, Nemer et al. (2002) verificaram sobrevivência de $80 \%$ para esta espécie, após três meses de plantio, também em clareiras originárias de exploração florestal. Estes resultados confirmam a adaptabilidade desta espécie em clareiras.

Caryocar villosum foi a espécie com taxa de sobrevivência mais baixa (47\%), devido principalmente à severa herbivoria observada em campo. Bagassa guianensis também sofreu ataques de herbívoros, mas apresentou sobrevivência relativamente alta (89\%), bem próxima à taxa (88\%) observada por Carvalho et al. (2001) em plantio com 6 anos de idade, em plena luz, na regiáo do Tapajós. Segundo Sabogal et al. (2006), B. guianansis e $C$. goeldiana foram as espécies que apresentaram melhor desenvolvimento em enriquecimentos de capoeiras avaliados nos estados do Amazonas, Mato Grosso, Pará e Rondônia.

Manilkara huberi, Astronium gracile e Pouteria bilocularis apresentaram sobrevivência de $87 \%, 90 \%$ e $82 \%$, respectivamente, pois mesmo sendo espécies pertencentes ao grupo de tolerantes à sombra, se beneficiam das condiçóes de alta luminosidade proporcionada pelas clareiras.

Tabebuia impetiginosa (Figura 3) teve taxa de 93\%, próxima àquela observada por Serrão et al. (2003) para Tabebuia serratifolia $(91 \%)$ em parcelas localizadas no centro de clareiras originárias de exploração seletiva, na região do Moju, PA. Esses resultados mostram que a espécie possui grande adaptabilidade em condiçóes de alta luminosidade, podendo ser indicada para plantios em clareiras. Em projetos de reposição florestal avaliados por Galeão et al. (2006) na região de Santarém, PA, a espécie T. serratifolia, plantada em linhas abertas em capoeiras altas, apresentou sobrevivência de $88 \%$. Nos projetos avaliados em Breves, PA, a sobrevivência da espécie foi de $94 \%$ em plantio puro em pleno sol, com 7 anos de idade.

Schulze et al. (2008) fizeram uma análise abrangente sobre a exploração das espécies Tabebuia serratifolia e Tabebuia impetiginosa na Amazônia brasileira, preocupandose principalmente com a alta taxa de colheita da madeira e com a possível exaustấo do gênero na regiấo. Esses autores, embora sem base científica sólida sobre a ecologia dessas espécies, comentam que, na melhor das hipóteses, apenas um indivíduo de uma dessas duas espécies, em cada 10 hectares, poderia atingir o tamanho de árvore adulta, e que isso poderia acontecer após um século ou mais de vida. Até agora, não há estudos que justifiquem esse comentário. Acrescentam que a regeneração natural dessas espécies, após a exploração, não seria suficiente para restaurar a estrutura da sua populaçáo original e concluem que o manejo sustentável do gênero Tabebuia requer uma combinação de plantios de enriquecimento e condução da regeneraçấo natural das espécies, em áreas exploradas.

O presente estudo já vem contribuindo para aumentar o conhecimento em relação ao enriquecimento e condução de plantas em clareiras oriundas de exploração florestal. E considerando a taxa de sobrevivência observada no presente estudo para as mudas de T. impetiginosa plantadas em clareiras, é possível assegurar que a estrutura da população da espécie poderá ser restaurada e até ter sua abundância aumentada na área. O desempenho da espécie nas clareiras e o seu manejo são objetos de outros estudos científicos, que estão em andamento neste mesmo projeto.

No trabalho realizado por Nemer et al. (2002), Pseudopiptadenia suaveolens mostrou uma média de sobrevivência de $80 \%$ após três meses de plantio. Segundo Serrão et al. (2003), essa espécie se adapta melhor a condiçôes de alta luminosidade, sendo sua sobrevivência maior no centro de clareiras quando comparada com plantios no interior da floresta. Essa informaçáo pode ser confirmada com os resultados obtidos no presente estudo, onde a sobrevivência de P. suaveolens foi de $100 \%$. 


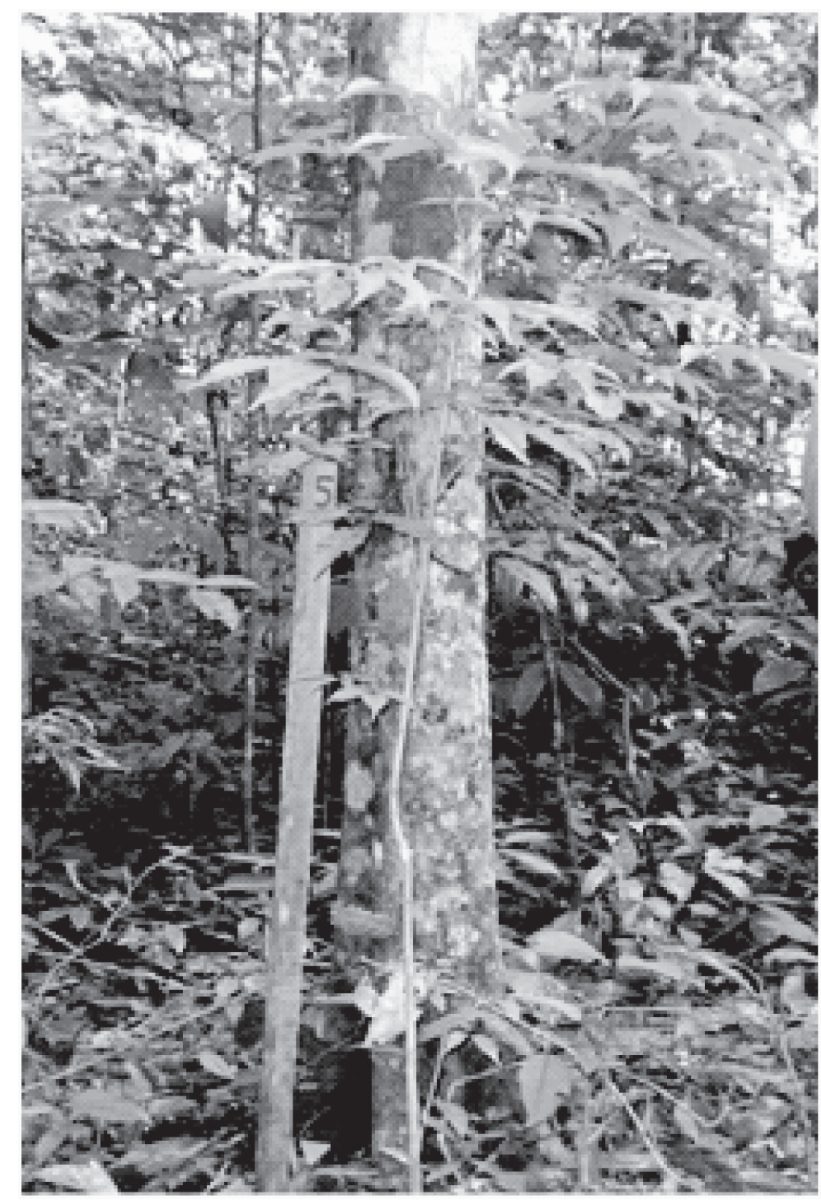

Figura 3: Tabebuia impetiginosa (Mart. Ex DC.) Standl.

Cordia goeldiana (Figura 4), no estudo de Tanaka e Vieira (2006) sobre a sua autoecologia em plantio de enriquecimento em linha em floresta primária no município de Aripuanã no estado do Amazonas, mostrou ser exigente quanto à radiação solar direta e difusa e foi considerada uma espécie heliófila, oportunista de clareira. Segundo Carpanezzi et al. (1983), Cordia goeldiana é uma espécie indicada para plantaçôes devido às suas características silviculturais de se adaptar a diferentes tipos de plantios como, por exemplo, nos plantios em linhas abertas em capoeiras em Belterra, onde a sua sobrevivência foi acima de 90\%. Segundo Sabogal et al. (2006), na Fazenda Treviso, no município de Belterra, PA, a espécie apresentou bom desenvolvimento, plantada em enriquecimento de capoeiras. Nos plantios avaliados por Galeão et al. (2006) em plantaçôes em linhas abertas em capoeiras altas na regiáo de Santarém, PA, C. goeldiana apresentou sobrevivência de $88 \%$ aos 6 anos de idade. No presente estudo, a sobrevivência dessa espécie foi de $89 \%$, o que confirma a sua preferência por locais de alta luminosidade. Segundo Jennings et al. (2001), em plantio realizado em clareiras em uma floresta na localidade de Revolta, município de Belterra, PA, C. goeldiana sofreu

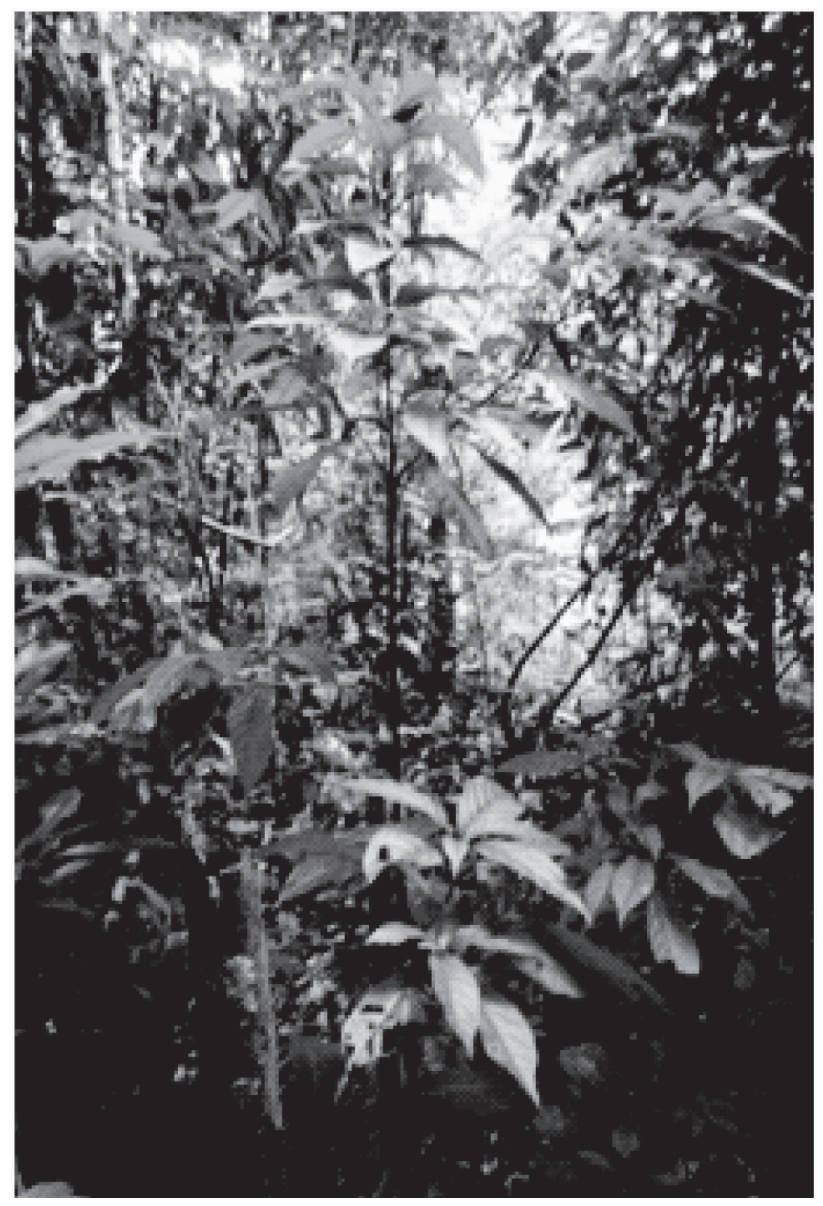

Figura 4: Cordia goeldiana Huber

ataques de herbívoros em alta proporçáo. No presente estudo náo foram registrados ataques de herbívoros a essa espécie.

As espécies Parkia gigantocarpa, Simarouba amara, Sterculia pilosa e Laetia procera que também pertencem ao grupo de espécies intolerantes à sombra, mantiveram taxas de sobrevivência elevadas nas clareiras, no presente estudo, variando de 80 a $94 \%$.

Dinizia excelsa e Schefflera morototoni, apesar de pertencerem ao grupo de espécies intolerantes à sombra, apresentaram sobrevivência de 78\% e 75\%, respectivamente, taxa considerada baixa quando comparada com as outras espécies avaliadas. Há a possibilidade dessas duas espécies também sofrerem herbivoria, segundo informaçôes dos operários de campo, porém isso ainda não foi constatado durante as avaliaçóes. Galeão et al. (2006) registraram uma taxa de sobrevivência de apenas $42 \%$ para $S$. morototoni em plantio puro em pleno sol, aos 14 anos de idade, na regiáo do Moju, PA. Os autores não comentam sobre a possível causa da baixa sobrevivência. 


\section{CONCLUSÕES}

Com base na taxa de sobrevivência no período de 11 meses e 16 dias após o plantio, as espécies Schizolobium amazonicum (Huber) Ducke, Cedrela odorata L., Jacaranda copaia (Aubl.) D. Don, Manilkara huberi (Ducke) A. Chev., Astronium gracile Engl., Pouteria bilocularis (H. Winkl.) Baehni, Tabebuia impetiginosa (Mart. Ex DC.) Standl., Pseudopiptadenia suaveolens (Miq.) J. W. Grimes, Cordia goeldiana Huber, Parkia gigantocarpa Ducke, Simarouba amara Aubl., Sterculia pilosa Ducke, Laetia procera (Poepp) Eich., Dinizia excelsa Ducke e Schefflera morototoni (Aubl.) Lecne Planch podem ser indicadas para enriquecimento em clareiras formadas pela exploraçáo de impacto reduzido.

As espécies Caryocar villosum (Aubl.)Pers. e Bagassa guianensis Aubl. devem ser evitadas em plantios em clareiras por sofrerem ataques de herbívoros, embora B. guianensis tenha apresentado alta taxa de sobrevivência.

Estudos complementares, principalmente relacionados ao crescimento das mudas dessas espécies selecionadas, devem ser desenvolvidos em períodos mais longos, para confirmar sua utilização em plantios de enriquecimento de clareiras oriundas de exploraçáo florestal, como alternativa para aumentar a produtividade e o valor econômico das florestas naturais manejadas na Amazônia brasileira.

\section{BIBLIOGRAFIA CITADA}

Carpanezzi, A.A.; Yared, J.A.G.; Brienza Júnior, S.; Marques, L.C.T.; Lopes, J.C.A. 1983. Regeneração Artificial de Freijó (Cordia goeldiana Huber). Belém: EMBRAPA - CPATU.

Carvalho, J.O.P. 2000. Classificação em grupos ecológicos das espécies mais importantes em uma área da Floresta Nacional do Tapajós. Belém: Embrapa Amazônia Oriental.

Carvalho, J.O.P. 1992. Structure and dynamics of a logged over Brazilian Amazonian rain Forest. D.Phil. Thesis. University of Oxford. Oxford, UK. 215 pp.

Carvalho, J.O.P. 2001. Estrutura de matas altas sem babaçu na Floresta Nacional do Tapajós, p. 277-290. In: J.N.M. Silva, J.O.P. Carvalho, J.A.G. Yared (eds.). A silvicultura na Amazônia oriental: contribuiçóes do Projeto Embrapa/DFID. Belém: Embrapa Amazônia Oriental/DFID.

Carvalho, J.O.P.; Carvalho, M.S.P.; Baima, A.M.V.; Miranda, I.L.; Soares, M.H.M. 2001. Informaçôes básicas sobre ecologia e silvicultura de cinco espécies arbóreas da Amazônia brasileira. Belém: Embrapa Amazônia Oriental (Documentos, 101).

Galeão, R.R.; Carvalho, J.O.P.; Yared, J.A.G.; Marques, L.C.T.; Costa Filho, P.P. 2006. Diagnóstico dos projetos de reposiçáo florestal no estado do Pará. Revista de Ciências Agrárias 45: 101-120.

Gasparin, E.; Araújo, M.M.; Silva, M.G.; Carvalho, J.O.P.; Ferreira, J.E.R. 2008. Avaliação do desempenho de paricá (Schizolobium parahyba var. amazonicum (Huber ex Ducke) Barneby) em plantio irrigado no oeste do Pará, p. 100-106. In: 4o. Simpósio Latino- americano sobre Manejo Florestal, 2008, Santa Maria, RS, Brazil. Universidade Federal de Santa Maria,

Jennings, S.B.; Lopes, J.C.A.; Brown, N.D.; Whitmore, T.C. 2001 Desempenho comparativo de mudas de espécies florestais em gradiente microclimático criado experimentalmente, p.227251. In: J.N.M. Silva, J.O.P. Carvalho, J.A.G. Yared (eds.). A silvicultura na Amazônia oriental: contribuiçōes do Projeto Embrapa/DFID. Belém: Embrapa Amazônia Oriental/DFID.

Lamprecht, H. 1990. Silvicultura nos trópicos: ecossistemas florestais e respectivas espécies arbóreas - possibilidades e métodos de aproveitamento sustentado. Eschborn: Deutsche Gesellschaft für Technische Zusammenarbeit (GTZ) GmbH. 343 pp.

Leal, G.L.R. 2000. Paragominas: A realidade do pioneirismo. Alves. Belém. 498 pp.

Menezes-Filho, L.C. de L.; Ferraz, P. de A.; Pinha, J.F.M.; Ferreira, L.A.; Brilhante, N.A. 1995. Comportamento de 24 Espécies Arbóreas Tropicais Madeireiras Introduzidas no Parque Zoobotânico, Rio Branco - Acre. Rio Banco: Universidade Federal do Acre. Parque Zoobotânico, V1. p. 77 - 81.

Nemer, T.C.; Jardim, F.C. da S.; Serrâo, D.R. 2002. Sobrevivência de Mudas da Regeneração Natural de Espécies Arbóreas Três Meses Após o Plantio em clareiras de Diferentes Tamanhos, Moju, PA. Revista Árvore, 26: 127 - 221.

Ohashi, S.T.; Costa, L.G.S.; Pedroso, L.M. 1993. Enriquecimento de Floresta Tropical Mecanicamente Explorada com espécies Cedrela odorata L. (cedro) e Carapa guianensis AUBL. (andiroba), no planalto de Curuá-Una, Pará, Brasil. Boletim Faculdade de Ciências da Administração de Pernambuco, 21: 1-21.

Oliveira, L.C. de; Couto, T.Z. do; Silva, J.N.M.; Carvalho, J.O.P. 2006. Exploraçáo Florestal e Eficiência dos Tratamentos Silviculturais Realizados em uma Área de 136 ha na Floresta Nacional do Tapajós, Belterra - Pará. Revista de Ciências Agrárias, 46: 195-213.

Rodrigues, T.E.; Silva, R.C.; Silva, J.M.L.; Oliveira Júnior, R.C.;Gama, J.R.N.F.; Valente, M.A. 2003. Caracterização e classificação dos solos do município de Paragominas, Estado do Pará. Belém: Embrapa Amazônia Oriental. 51p. (Documentos 162).

Sabogal, C.; Almeida, E.; Marmillod, D.; Carvalho, J.O.P. 2006. Silvicultura na Amazônia Brasileira: avaliação de experiências e recomendaçóes para implementação e melhoria dos sistemas. Belém, CIFOR. 190 pp.

Schulze, M.; Grogan, J.; Uhl, C.; Lentini, M.; Vidal, E. 2008. Evaluating ipê (Tabebuia, Bignoniaceae) logging in Amazonia: Sustainable management or catalyst for forest degradation? Biological Conservation, 141: 2071-2085.

Serrão, D.R.; Jardim, F.C. da S.; Nemer, T.C. 2003. Sobrevivência de seis espécies florestais em uma área explorada seletivamente no Município de Mojú, Pará. Cerne, 9: 153-163.

Silva, J.N.M. 2001. Manejo Florestal. Embrapa Amazônia Oriental (Belém, PA). 3 ed., Brasília: Embrapa Informação Tecnológica. $49 \mathrm{pp}$.

Sombroek, W.G. 1986. Soil of the Amazon region. In: H. Sioli (ed.). The Amazon Basin: Landscape ecology and hydrology of a mighty river. p. 122-135. 
Swaine, M.D.; Whitmore, T.C. 1988. On the definition of ecological species groups in tropical rain forests. Vegetatio, 75: 81-86.

Tanaka, A.; Vieira, G. 2006. Autoecologia das espécies florestais em regime de plantio de enriquecimento em linha na floresta primária da Amazônia Central. Acta Amazonica, 36: 193-204.

Veloso, H.P.; Rangel Filho, A.L.R.; Lima, J.C.A. 1991. Classificaçâo da vegetaçâo brasileira adaptada a um sistema universal. IBGE, Departamento de Recursos Naturais e Estudos Ambientais, Rio de Janeiro, $124 \mathrm{pp}$.

Vidal, E.; Viana, V.M.; Batista, J.L.F. 2002. Crescimento de Floresta Tropical Três Anos Após Colheita de Madeira Com e Sem
Manejo Florestal na Amazônia Oriental. Scientia Forestalis, 61: 133-143.

Watrin, O.S.; Rocha, A.M.A. 1992. Levantamento de vegetação natural e uso da terra no Município de Paragominas (PA) utilizando imagens TM/Landsat. Belém: EMBRAPA-CPATU. (Boletim de Pesquisa, 124).

Recebido em 03/05/2009

Aceito em 28/10/2009 